\title{
Scaffold Seeding
}

National Cancer Institute

\section{Source}

National Cancer Institute. Scaffold Seeding. NCI Thesaurus. Code C112956.

Addition of living cells to a biocompatible scaffold. 